DOI: 10.12731/2658-6649-2020-12-2-41-72

УДК 616.89

\title{
СУЛЬБУТИАМИН \\ В ПСИХИАТРИИ, НАРКОЛОГИИ, НЕВРОЛОГИИ И ОБЩЕСОМАТИЧЕСКОЙ МЕДИЦИНЕ (ОБЗОР ЛИТЕРАТУРЫ)
}

Беккер Р.А., Быков Ю.В.

Цель исследования: представить читателю данные о фармакологической активности сульбутиамина (одного из липофильных производных тиамина), о механизмах его терапевтического эффекта, о его показаниях к применению и о доказательной базе для его применения в психиатрии, наркологии и неврологии, а также при некоторых общесоматических патологиях.

Методология проведения работы: мы провели поиск и изучение литературных данных о тиамине и сульбутиамине в поисковых системах и базах данных PubMed, Google Scholar, Science Direct, с использованием соответствующих ключевых слов.

Результаты: найденные нами в ходе составления настоящего обзора литературные данные свидетельствуют о том, что сульбутиамин может обладать рядом иченных для клинической практики свойств, в частности, антиоксидантным, нейропротективным, ноотропным, психостимулирующим, энергизирующим и антиастеническим действием и, возможно, также умеренными антидепрессивными, анксиолитическими и анальгетическими свойствами. Он может быть эффективным в составе комплексной терапии деменции Альизгеймера, депрессивных и тревожных расстройств, расстройств аутистического спектра, синдрома дефицита внимания и гиперактивности, астенических состояний разного генеза и др.

Область применения результатов: результаты этого обзора заслуживают самого широкого применения в психиатрии, наркологии и неврологии.

Ключевые слова: сульбутиамин; тиамин; липофильные аналоги тиамина; астения; депрессивные расстройства; расстройства аутистического спектра; синдром дефицита внимания и гиперактивности. 


\title{
SULBUTHIAMINE \\ IN PSYCHIATRY, ADDICTION MEDICINE, NEUROLOGY AND GENERAL MEDICINE (SCIENTIFIC REVIEW)
}

\author{
Bekker R.A., Bykov Yu.V.
}

Purpose: To provide the reader the comprehensive scientific data regarding the pharmacological activity of sulbuthiamine (one of the lipophilic derivatives of thiamine), the putative mechanisms of its therapeutic effect, indications for its use in medicine, and, finally, the existing evidence base for its use in psychiatry, addiction medicine and neurology, as well as in some somatic pathologies.

Methodology: To this goal, we have searched and studied the available scientific data on thiamine and sulbutiamine using search engines and databases PubMed, Google Scholar, Science Direct, with the use of corresponding keywords.

Results: The data we have obtained in the process of compiling this review indicate that sulbuthiamine can have several properties which are valuable for clinical practice. It can have antioxidant, neuroprotective, nootropic, psychostimulant, energizing and antiasthenic effects and, possibly, also moderate antidepressant, anxiolytic and analgesic properties. It might be effective as a part of combination therapy in Alzheimer dementia, major depression, anxiety disorders, autistic spectrum disorders, attention deficit hyperactivity disorder, asthenia of different origin, and so on.

Practical implications: The results we have presented in this review deserve the widest application in psychiatry, addiction medicine and neurology.

Keywords: sulbuthiamine; thiamine; lipophilic thiamine analogues; asthenia; depressive disorders; autism spectrum disorders; attention deficit hyperactivity syndrome.

\section{Введение и историческая справка}

История изучения липофильных производных тиамина восходит к 1950-м годам в Японии [1]. В те времена в этой стране была весьма распространена болезнь бери-бери, связанная с дефицитом тиамина и проявляющаяся прежде всего болезненной периферической полинейропатией, дилатационной кардиомиопатией с сердечной недостаточностью, отёками, анорексией, тяжёлыми паралитическими запорами, нарушениями функции ЦНС (в диапазоне от депрессии, до спутанности сознания по 
типу описанной позже энцефалопатии Вернике, также относящейся к тиамин-дефицитным состояниям, психозов, деменции), иногда возникновением слепоты или глухоты. Столь высокая распространённость бери-бери в послевоенной Японии была обусловлена спецификой питания японцев преимущественно полированным рисом, в котором, в отличие от неполированного риса, ржи или пшеницы, содержание тиамина очень низкое [1].

Для лечения этих состояний применяли высокие дозы тиамина, вводимые парентерально (внутримышечно или внутривенно). Однако японских учёных не устраивала недостаточная эффективность терапии тиамином, поскольку из-за низкой липофильности он имел ограниченное проникновение в клетки, даже после парентерального введения больших доз. А это означало, что для коррекции выраженного дефицита тиамина требовалось много времени (много дней введения высоких доз тиамина), и за это время изменения в ЦНС могли стать необратимыми. Кроме того, длительное парентеральное введение препарата было попросту неудобно и болезненно, приводило к снижению комплаентности больных, развитию флебитов, постинъекционных абсцессов. А при приёме внутрь тиамин плохо всасывается, опять же из-за низкой липофильности и из-за быстрого насыщения специализированной транспортной системы (усваиваются только обычно присутствующие в пище количества, но не большие, фармакологические дозы) [1].

Осознав эту проблему, японские учёные стали экспериментировать с различными модификациями молекулы тиамина, стремясь создать такое соединение тиамина, которое было бы одновременно и высоколипофильным и потому хорошо всасывающимся в ЖКТ (то есть пригодным для перорального приёма), а также хорошо проникающим через липидные мембраны клеток путём пассивной диффузии (что позволяет быстро доставить в клетку большую его дозу, обойдя ограничения специализированного активного транспорта), и способным в клетке быстро гидролизоваться с высвобождением биологически активного тиамина [1].

Первым шагом на этом пути был так называемый аллитиамин - открытое в 1953 году природное соединение тиамина, обнаруженное японскими учёными в чесноке, и представляющее собой соединение тиамина с диаллил-сульфидом (пахучим веществом чеснока) [2]. Аллитиамин намного более липофилен, чем тиамин, и поэтому быстро всасывается в ЖКТ, легко проникает в клетки, и легко гидролизуется в клетках до активного тиамина. В свою очередь, к изучению чеснока как возможного источника соединений тиамина учёных подтолкнуло старинное японское поверье о том, что будто бы чеснок способен излечивать бери-бери (на самом деле это не так: тиамина в нём мало) [3]. 
В дальнейшем учёные показали, что аллитиамин обладает активностью витамина $\mathrm{B}_{1}$ даже у тех организмов, которые не способны его гидролизовать, т. е. вполне способен функционально замещать тиамин [4]. Это привело учёных к мысли поискать другие аналогичные липофильные соединения, обладающие такими свойствами, но более простые в синтезе, чем аллитиамин. Одним из ранних экспериментов этого рода были попытки применения тиамина пропил-дисульфида, или так называемого просультиамина, начавшиеся ещё в 1958 году [5].

Довольно быстро было показано, что дисульфидные соединения тиамина, такие, например, как просультиамин (тиамина пропил-дисульфид) или аллитиамин (тиамина диаллил-дисульфид) не просто более эффективны, чем S-ацильные производные тиамина, но и обладают некоторыми дополнительными фармакологическими свойствами, такими, как антиоксидантная активность (обусловленная способностью этих соединений образовывать в клетке, помимо тиамина, также сероводород - сильный восстановитель и важный внутриклеточный газообразный медиатор сигналов) и способность увеличивать мышечную выносливость, уменьшать астенизацию больных [6].

Кроме того, оказалось, что дисульфидные соединения тиамина обладают дезинтоксикационными свойствами, в частности, могут защищать нервные клетки и клетки ткани печени от отравления свинцом, трихлорэтиленом, цианидом [6]. Помимо этого, дисульфидные соединения тиамина легко восстанавливаются до активных форм витамина $\mathrm{B}_{1}$ в присутствии цистеина или глютатиона, в то время как $\mathrm{S}$-ацильные соединения тиамина требуют гидролиза в печени при участии ферментов [6].

На основе этих данных, учёными были последовательно созданы сначала ещё более липофильный по сравнению с аллитиамином и просультиамином О-бутирилтиамина дисульфид (получивший в Японии сокращённое название BuTDS) $[7,8,9,10]$ и затем О-изобутирилтиамина дисульфид [11], а затем и герой нашего повествования - сульбутиамин, являющийся димером из двух молекул О-изобутирилтиамина, соединённых дисульфидным мостиком [12]. Как видно из приведённых ссылок, первое упоминание сульбутиамина в литературе относится к 1973 году [11].

\section{Фармакодинамика и фармакокинетика}

Сульбутиамин - это высоколипофильный синтетический аналог тиамина (витамина $\mathrm{B}_{1}$ ) - димер из двух молекул тиамина изобутирата, соединённых дисульфидным мостиком [13]. В организме сульбутиамин способен 
гидролизоваться, превращаясь в тиамин и затем фосфорилируясь в его биологически активные коферментные формы (тиамина монофосфат, затем тиамина дифосфат и тиамина трифосфат) [14].

Благодаря своей высокой липофильности сульбутиамин, в отличие от тиамина, быстро и легко всасывается в ЖКТ, хорошо проникает через гематоэнцефалический барьер (ГЭБ) [15]. Высокая липофильность сульбутиамина облегчает также его проникновение через липидный бислой плазматических мембран клеток и клеточных органелл путём пассивной диффузии, в отличие от тиамина, который для своего проникновения в клетку нуждается в активном транспорте с помощью специализированного высокоаффинного транспортёра, имеющего, однако, ограниченную производительность (т.е. быстро достигающего насыщения). Так, показано, что сульбутиамин в 20 раз активнее тиамина проходит через липидный бислой мембран клеток культуры нейробластомы [16].

В отличие от амфифильного S-ацильного производного тиамина бенфотиамина (S-бензоилтиамина O-монофосфата), приём которого приводит к повышению концентрации тиамина и его фосфатов только в периферических тканях и в печени, приём сульбутиамина, так же как и приём двух других высоколипофильных производных тиамина дисульфида, аллитиамина и фурсультиамина, приводит к увеличению концентрации тиамина и его фосфатов также и в ЦНС [17].

После приёма сульбутиамина внутрь $\mathrm{C}_{\text {max }}$ (пиковая концентрация) его в крови достигается через 1-2 часа, а $\mathrm{T}_{1 / 2}$ (период полувыведения) препарата составляет около 5 часов [18]. Выводится сульбутиамин с мочой, как в неизменённом виде, так и в виде метаболитов тиамина [13].

\section{Механизмы терапевтического эффекта}

На макроуровне (на уровне анатомических структур мозга и отдельных клеток) основными мишенями воздействия сульбутиамина являются нейроны ретикулярной формации, ответственные за поддержание бодрствования и бдительность; клетки гиппокампа, благодаря которым реализуются сложные механизмы наученного реактивного и аффективного поведения; клетки Пуркинье коры головного мозга, которые образуют интегративный слой коры и участвуют в регуляции мотивации и контроле мышечного тонуса и двигательных реакций [13].

Ниже мы подробно рассмотрим механизмы реализации этих эффектов сульбутиамина на микроуровне, на уровне отдельных биохимических процессов. 


\section{Влияние на холинергическую нейропередачу}

Сульбутиамин способен улучшать память и когнитивные функции в экспериментах на животных. Этот эффект проявляется как на здоровых животных, так и в экспериментальных моделях болезни Альцгеймера (БА). Показано, что этот эффект сульбутиамина опосредуется усилением холинергической нейропередачи в гиппокампе и повышением захвата и утилизации холина нервными клетками с соответствующим увеличением биосинтеза и высвобождения ацетилхолина. Это может частично объяснять положительное влияние сульбутиамина на память, когнитивные функции и концентрацию внимания [19].

\section{Влияние на глутаматергическую нейропередачу}

Сульбутиамин увеличивает активность глутаматергической системы в префронтальной коре. Это тоже может вносить свой вклад в положительное влияние этого препарата на память, когнитивные функции и концентрацию внимания [20, 21, 22, 23].

\section{Влияние на дофаминергическую нейропередачу}

Помимо своего действия на холинергические и глутаматергические процессы, сульбутиамин увеличивает выделение дофамина в префронтальной коре. Он также повышает плотность дофаминовых рецепторов $\mathrm{D}_{1}$ подтипа в префронтальной коре. Это тоже может частично объяснять положительное влияние сульбутиамина на когнитивные функции и концентрацию внимания, а также его эффективность при синдроме дефицита внимания и гиперактивности (СДВГ) [24, 25].

\section{Влияние на ГАМКергическую нейропередачу}

Сульбутиамин и тиамин являются предшественниками тиамина трифосфата, который является активатором ГАМК-связанных хлорных каналов в нейронах, тем самым ускоряя передачу сигналов возбуждения между клетками [26].

\section{Специфическая тиаминергическая нейропередача}

В последнее время появились данные и о том, что тиамин, возможно, сам по себе является одним из важных нейромедиаторов (возможно, не менее важным, чем моноамины и ацетилхолин). Он имеет собственные механизмы выделения из нервных клеток и обратного захвата, причём во многих случаях наблюдается его совместное выделение (ко-секреция) в 
синаптическую щель вместе с ацетилхолином и с моноаминами. Обнаружены также специфические мембранные рецепторы к тиамину и тиаминоподобным соединениям, экспрессируемые в нервной ткани (TAS2R1) [26].

Возможно, что влияние сульбутиамина на эту специфическую тиаминергическую нейропередачу также является одним из важных механизмов его терапевтического действия [26].

\section{Антиоксидантное и нейропротективное действие}

Показано, что сульбутиамин и $\mathrm{N}$-ацетилцистеин (АЦЦ), в отличие от тиамина, являясь донорами сульфгидрильных групп, являются эффективными антиоксидантами и уменьшают оксидативный стресс, эксайтотоксичность глутамата, образование свободных радикалов, активацию проапоптотических белков и в конечном итоге апоптоз нейронов и клеток сетчатки. При этом сульбутиамин не только повышает концентрацию глютатиона и активность глютатион-сульфотрансферазы в клетках, подобно АЦЦ, но и увеличивает активность таких важных защитных ферментов, как каталаза, гемоксигеназа-1, и важного антиапоптотического белка $\mathrm{Nrf} 2$ [27]. Таким образом, сульбутиамин может оказывать ценное в клинике нейро- и ретинопротективное действие, например, при диабетической ретинопатии [27].

Другими авторами показано, что сульбутиамин способен оказывать нейропротективное действие при экспериментальном ишемическом инсульте у животных, а также в экспериментальной модели ишемии в культуре пирамидальных нейронов коры (депривация кислорода и глюкозы) [28].

\section{Влияние на биосинтез факторов роста нейронов}

Показано, что сульбутиамин способен защищать от апоптоза нейроны и клетки сетчатки, искусственно лишённые таких ростовых факторов, как BDNF, NGF, VEGF (выращиваемые на искусственно обеднённой среде, без добавления сыворотки крови, или в условиях блокады производства факторов роста применением антисмысловой РНК), а в нормальных условиях способен увеличивать выработку этих факторов роста и стимулировать нейрогенез [29].

А ведь мы сегодня знаем, что повышение секреции BDNF и других факторов роста, по всей вероятности, является общим конечным механизмом реализации антидепрессивного эффекта всех известных классов антидепрессантов (АД), а также лития, вальпроатов, некоторых атипичных антипсихотиков (ААП) [30]. 
Это заставляет предположить, что сульбутиамин также может если и не обладать самостоятельной антидепрессивной активностью, то, во всяком случае, может способствовать усилению антидепрессивного эффекта других препаратов [30].

\section{Влияние на циркадные ритмы и архитектонику сна}

Показано, что сульбутиамин способен увеличивать время бодрствования, уменьшать дневную сонливость и потребность во сне и улучшать показатели индекса бодрствования на ЭЭГ в период активного состояния, одновременно улучшая фазовую структуру сна, у экспериментальных приматов (макак) [31].

Также показано, что сульбутиамин способен нормализовывать циркадные ритмы, в том числе ритмы и архитектонику сна, и улучшать интеллектуальные функции больных, уменьшая десинхроноз [15].

\section{Терапевтические мишени сульбутиамина в психиатрической практике Биполярное аффективное расстройство и униполярные депрессивные расстройства}

Сульбутиамин и бенфотиамин способны тормозить активность фермента гликоген-синтазы киназы 3-бета (GSK3ß) [32], важного фермента, нарушения регуляции которого играют роль в патогенезе БА, а также в патогенезе биполярного аффективного расстройства (БАР), униполярных депрессивных расстройств, шизофрении и расстройств шизофренического спектра (РШС), тревожных расстройств (ТР) [33].

Известно, что торможение активности фермента GSK3 $\beta$ постулируется в качестве одного из важных механизмов нормотимического, антиманиакального, нейропротективного и антидепрессивного действия препаратов лития [34], вальпроатов [35], кветиапина [36], оланзапина и клозапина [37], а возможно, и других ААП и нормотимиков (НТ) [38].

Описан один интересный пациент с БАР 2-го типа с преобладанием депрессий, который начал самовольно употреблять сульбутиамин (доступный в качестве БАД без рецепта во многих западных странах) на почве неэффективности предшествующей терапии АД, ААП и НТ. Начав принимать сульбутиамин, этот пациент быстро отметил его положительное антидепрессивное действие. На этом основании он начал самовольно увеличивать принимаемые им дозы сульбутиамина, вплоть до 2000 мг/сут. Интересно, что сами по себе такие дозы сульбутиамина не привели к развитию каких-либо вредных последствий у этого пациента. Однако пациент, считая, что ему помогает только сульбутиамин, прекратил принимать НТ и ААП и перестал 
регулярно посещать психиатра с профилактическими визитами. Это закономерно привело к развитию у него маниакального эпизода [39].

В одной из статей утверждается, что сульбутиамин сам по себе не обладает антидепрессивным эффектом, но может положительно влиять на поведенческие реакции и на уровень энергии и активности у пациентов с депрессией, уменьшать астению, улучшать когнитивные функции у этих пациентов. Потенциально это способно дать лучшую адаптацию пациентов в социальной, профессиональной и семейной сферах после перенесённого депрессивного эпизода [40].

Важно также отметить, что у пациентов с депрессией, вследствие снижения аппетита, повышенного влечения к сладкому и нередкого злоупотребления алкоголем, дефицит тиамина встречается часто. Он может усугублять депрессивную симптоматику и вызывать резистентность к терапии АД, а порой даже может служить причиной развития энцефалопатии Вернике [41].

Порог подозрения на дефицит тиамина у пациентов с депрессией должен быть снижен. Во всех случаях депрессии, подозрительных на сопутствующий дефицит тиамина, назначение тиамина и его липофильных производных должно быть произведено как можно скорее, во избежание необратимых последствий [41].

\section{Расстройства пищевого поведения}

Расстройства пищевого поведения (РПП), такие, как нервная анорексия (НА), нервная булимия (НБ) и компульсивное переедание (КП), также могут сопровождаться выраженным дефицитом витамина $\mathrm{B}_{1}$, вплоть до развития энцефалопатии Вернике [41].

В случае НА это обусловлено снижением поступления тиамина с пищей, а также нередким злоупотреблением «потогонными» физическими упражнениями (потеря тиамина с потом), слабительными и мочегонными, вызыванием рвоты (потери тиамина с калом, мочой и рвотными массами). В случае НБ это обусловлено необычным составом рациона, несбалансированным, богатым простыми углеводами, а также частыми периодами самоограничения в еде вплоть до полного голодания, злоупотреблением слабительными и мочегонными, вызыванием рвоты. В случае КП имеет значение несбалансированность диеты (к самоограничению и «чисткам» эти пациенты, в отличие от булимиков, не прибегают) [41].

В подобных случаях, а также при любых других психических расстройствах, сопровождающихся нарушением пищевого поведения, снижением аппетита или отказом от еды, порог для назначения тиамина и его 
липофильных производных также должен быть низким, а уровень подозрения на его возможный дефицит - высоким [41].

МакКормик и соавторы отмечают также, что многие пациенты с психическими расстройствами страдают ожирением или метаболическим синдромом (МC), и вследствие этого нередко подвергаются бариатрическим операциям на ЖКТ. А бариатрические операции и вызываемая ими мальабсорбция тиамина являются независимым фактором риска тиамин-дефицитных состояний [41].

\section{Шизофрения и расстройства иизофренического спектра}

Имеются предварительные данные о том, что сульбутиамин улучшает память и когнитивные функции у пациентов с шизофренией и РШС [42]. Важно также иметь в виду, что у пациентов с шизофренией и РШС, вследствие их необычных пищевых пристрастий, нередкого отказа от еды по бредовым причинам или из-за наличия обонятельных и вкусовых галлюцинаций, а также вследствие вызываемого АП повышения аппетита на сладкое, дефицит тиамина встречается очень часто, и иногда приводит к развитию клинически выраженной энцефалопатии Вернике [43].

Так, описан 51-летний мужчина с шизофренией, не употреблявший алкоголя, у которого энцефалопатия Вернике развилась вследствие необычных пищевых пристрастий и пониженного питания. У этого пациента психотическая симптоматика не купировалась до тех пор, пока к лечению не был присоединён тиамин, а затем фурсультиамин [43].

Ещё более интересно то, что у многих больных шизофренией и РШС обнаруживаются нарушения в работе фермента транскетолазы и нарушения кислотно-основного баланса. Основываясь на этих данных, авторы одной статьи предложили в качестве адъювантной терапии к АП высокие дозы тиамина и фурсультиамина или сульбутиамина, а также ацетазоламид (диакарб), исправляющий патологический сдвиг $\mathrm{pH}$ ликвора. Они сумели показать, что такая терапия улучшает результаты лечения, причём как в отношении позитивной, так и в отношении негативной симптоматики, и способствует снижению резистентности к АП [44].

\section{Расстройства аутистического спектра}

Расстройства аутистического спектра (РАC) сопровождаются нарушениями обмена тиамина и содержания ряда микроэлементов в организме, а также изменениями в активности транскетолазы, ключевого тиамин-зависимого фермента [45]. 
Описана семья, в которой было двое детей с тяжёлой формой РАС (которая ранее классифицировалась бы как ранний детский аутизм - РДА), и один ребёнок с более лёгкой, высокофункциональной формой РАC, которая ранее классифицировалась бы как синдром Аспергера (СА). Мать этих детей страдала алкоголизмом. У всех этих детей, так же как и у их матери, обнаруживалась вегетативная дизавтономия (нарушения работы вегетативной нервной системы) и признаки дефицита витамина $\mathrm{B}_{1}$. Лечение этих детей липофильными производными тиамина (сульбутиамином, фурсультиамином) и нормализация их диеты привели к улучшению как симптоматики РАС, так и симптоматики вегетативной дизавтономии [46].

В другом интересном случае тяжёлая форма РАС (ранее классифицированная как РДА) у ребёнка оказалась связанной с перенесённой в раннем детстве энцефалопатией Вернике. Это было подтверждено с помощью MPТ [47]. Состояние этого ребёнка значительно улучшилось после лечения тиамином и сульбутиамином [47].

Авторы, описавшие данный клинический случай, подчеркнули важность дифференциальной диагностики истинных, или идиопатических, форм РАС, и псевдо-РАС, обусловленных перенесённой в раннем детстве энцефалопатией Вернике, необходимость включения энцефалопатии Вернике в круг дифференциальной диагностики при РАС, а также обратимость состояний псевдо-РАС, обусловленных энцефалопатией Вернике, при своевременном и энергичном лечении производными тиамина [47].

В одном пилотном исследовании 2002 года прицельно исследовалась эффективность фурсультиамина (тиамина тетрагидрофурфурил дисульфида) и сульбутиамина при лечении РАС. Были получены положительные результаты [48].

А автор другой статьи подчёркивает, что стволовые структуры мозга, которые в наибольшей степени затрагиваются при РАС, как раз в наибольшей степени чувствительны к дефициту тиамина. По его мнению, дефицит тиамина, как малая форма энцефалопатии Вернике, может лежать в основе многих случаев РАС [49].

\section{Синдром дефицита внимания и гиперактивности}

Показано, что повышенное потребление тиамина в детском возрасте способствует значительному смягчению симптоматики не только РАС, но и СДВГ. Липофильные производные тиамина, такие, как фурсультиамин (тиамина тетрагидрофурфурил дисульфид) и сульбутиамин, способны оказывать лечебное действие при этих состояниях [50]. 
Это подтверждается и в экспериментальной модели СДВГ, каковой являются мыши с генотипом DBA/2j [50]. У детей с так называемым «гиперкинетическим синдромом» (так раньше называли СДВГ) применение высоких доз витаминов группы В, и в частности липофильных аналогов витамина $\mathrm{B}_{1}$, вызывает улучшение концентрации внимания, снижение гиперактивности, улучшение успеваемости и обучаемости $[51,52,53]$.

\section{Деменции, в частности болезнь Альцгеймера}

Сульбутиамин, усиливая холинергическую, дофаминергическую и глутаматергическую нейротрансмиссию в префронтальной коре и гиппокампе, приводит к умеренному клиническому улучшению у больных с начальными и средними стадиями БА. Он также усиливает антидементное и нейропротективное действие мемантина и ингибиторов холинэстеразы (ИАХЭ), таких, как донепезил, ривастигмин, галантамин [54].

Аналогичное положительное влияние на течение БА в ранних стадиях оказывает и другое липофильное производное тиамина - фурсультиамин [55].

В экспериментах на трансгенных мышах с экспериментальным аналогом БА сульбутиамин и бенфотиамин оказались способны уменьшать отложения $\beta$-амилоида в клетках мозга мыши, тормозить прогрессирование поведенческих и когнитивных изменений и уменьшать активацию генов GSK3 $\beta$ (гликоген-синтазы киназа 3-бета) и пресенилина-1, играющих важную роль в патогенезе БА [32].

\section{Терапевтические мишени сульбутиамина в неврологической практике Астенический синдром}

Ещё в самом начале клинического изучения сульбутиамина, в 1979 году, было показано, что он способен эффективно уменьшать астенические явления, нервно-психическую и мышечную слабость [12].

Позднее эффективность сульбутиамина была подтверждена в большом числе РКИ при астениях различного генеза, например, при постинфекционной и послеродовой астении, при сексуальных расстройствах, а также при астении после больших физических нагрузок у спортсменов [56].

В целом ряде плацебо-контролируемых РКИ с использованием психометрических тестов и оценочных шкал была показана высокая эффективность сульбутиамина при симптоматической терапии функциональных астенических состояний [57]. Рассмотрим отдельные работы, как контролируемые, так и открытые, подробнее. 
Так, российскими исследователями показано, что в остром периоде инсульта у лиц с диагностированным астеническим синдромом сульбутиамин снижает выраженность астении и других коморбидных проявлений, улучшает неврологический статус. Препарат назначался в дозе 200 мг два раза в сутки в течение 4 недель [58].

В ещё одном открытом исследовании, в котором участвовали 58 подростков (15-18 лет), страдающих психическими расстройствами пограничного уровня с ведущим астеническим синдромом, сульбутиамин продемонстрировал выраженное антиастеническое, ноотропное, а также мягкое анксиолитическое и вегетотропное действие. При этом не наблюдалось каких-либо побочных эффектов (ПЭ) или отказов от лечения [59].

В другом неконтролируемом исследовании у амбулаторных геронтологических пациентов с астеническими расстройствами было показано, что, сульбутиамин в дозе 400 мг один раз в сутки не только купирует астенические проявления, но и улучшает когнитивные функции у пациентов пожилого и старческого возраста [60].

В ещё одном исследовании назначение сульбутиамина по 200 мг 2 раза в сутки привело к снижению выраженности астенической симптоматики у 30 пациентов, которые перенесли ишемический инсульт или острый инфаркт миокарда. Авторы отметили отсутствие у сульбутиамина каких-либо существенных ПЭ и возможность его комбинации с другими лекарственными средствами [61].

Сульбутиамин также оказался эффективен у пациентов с постинфекционной астенией. У них применение этого препарата купировало вялость, повышало аппетит и физическую выносливость [18].

Другой группой авторов было показано, что сульбутиамин даёт выраженное и стойкое улучшение состояния пациентов, перенёсших черепно-мозговую травму (ЧМТ). При этом наибольшей редукции под влиянием сульбутиамина подвергались именно симптомы посттравматической астении. В этом отношении сульбутиамин превосходил по эффективности пирацетам [62].

Также была показана эффективность и хорошая переносимость препарата сульбутиамин у пациентов с соматоформной вегетативной дисфункцией (СВД) и выраженной астенией. Эти авторы констатируют, что, по их мнению, сульбутиамин «обладает выраженным антиастеническим и вегетотропным эффектом, способствует нормализации фазовой структуры сна и общего фона настроения, а также улучшению качества жизни пациентов с астеническими состояниями разного генеза» [63]. 
В ещё одной работе было показано, что применение сульбутиамина в дозе 200 мг 2 раза в сутки на протяжении минимум 30 дней эффективно в лечении астенических состояний, возникающих на фоне различной соматической патологии. В той выборке пациентов, с которой работали авторы этой статьи, наилучший эффект от применения сульбутиамина наблюдался у тех пациентов, у которых астения сочеталась с бессонницей (диссомнией) и/или с тревожностью [64].

Авторы ещё одной статьи рекомендуют включать сульбутиамин в дозе 400-600 мг/сут в схему медикаментозного лечения пациентов, перенёсших инсульт и проходящих реабилитацию, с целью уменьшения проявлений постинсультной астении и облегчения процесса реабилитации [65].

В другой статье российских авторов отмечается, что применение сульбутиамина способствует улучшению координации движений, концентрации внимания, способности к запоминанию и воспроизведению информации, а также повышению устойчивости к развитию переутомления мышц, и в целом к воздействию различных стрессовых факторов [66].

Ещё одна группа российских авторов рекомендует с целью коррекции астенических проявлений и лёгких когнитивных нарушений (КН) у пациентов с начальными формами хронических сосудистых заболеваний головного мозга применять сульбутиамин курсами в дозе 200 мг 2 раза в день на протяжении 20 дней, в комбинации с дельтараном в дозе 0,3 мг интраназально утром в течение 10 дней [67].

Ещё один автор пишет, что сульбутиамин «оказывает положительное влияние на субъективное чувство, связанное с интеллектуально-психической деятельностью, ощущением жизненного тонуса, комфортностью осуществления произвольной интеллектуальной деятельности и моторики». Согласно его утверждению, «сульбутиамин интенсивно редуцирует астенические проявления, и почти в $50 \%$ случаев полностью выводит из состояния функциональной астении» [68].

Другой автор указывает, что комплексная терапия, включающая сульбутиамин, у пациентов с астеническим симптомокомплексом, развивающимся в рамках ТР, невротических и постстрессовых расстройств (то есть у пациентов, страдающих тем симптомокомплексом, который старые авторы когда-то называли «неврастенией»), даёт более выраженный клинический эффект, и быстрее приводит к уменьшению или даже полному исчезновению большинства симптомов как астенического симптомокомплекса, так и собственно ТР, невротического или постстрессового 
расстройства, в сопоставлении со стандартной комплексной терапией, не включающей сульбутиамин [69].

Кроме того, этим же автором показано, что сульбутиамин может обладать иммунорегулирующими свойствами. Он оказывает модулирующий эффект на процессы позитивной и негативной активации лимфоцитов, нормализует соотношение CD95/CD25 лимфоцитов и тормозит реализацию программы апоптоза иммунных клеток [69].

\section{Эпилепсия}

Приводятся данные о положительном влиянии сульбутиамина на память, концентрацию внимания и когнитивные функции, качество сна, а также об уменьшении проявлений астении и депрессии и о некотором уменьшении частоты судорожных припадков при включении этого препарата в состав комплексной терапии у пациентов с симптоматической фокальной эпилепсией [70].

\section{Диабетическая полинейропатия}

Будучи липофильным производным тиамина, хорошо проникающим в нервную ткань и способным метаболизироваться в тиамин, сульбутиамин закономерно улучшает функцию периферических нервов при диабетической полинейропатии, в патогенезе которой большую роль играет дефицит витамина $\mathrm{B}_{1}$. Наряду с улучшением клинических симптомов полинейропатии, в группе, получавшей сульбутиамин, были зарегистрированы также значительные улучшения электрофизиологических показателей (проводимости в нервном стволе), по сравнению с контрольной группой, получавшей тиамин [71].

\section{Болевые синдромы}

Ещё в 1973 году было показано, что сульбутиамин и другие липофильные производные тиамина обладают анальгетическими свойствами. Анальгетический эффект сульбутиамина и других липофильных производных тиамина проявляется не только при различных хронических болевых синдромах (ХБС), но и при экспериментально вызванной острой боли у добровольцев. Предполагается, что анальгетический эффект липофильных производных тиамина опосредуется модуляцией ими моноаминергической, глутаматергической и/или холинергической нейропередачи [11].

Сравнительно недавно, в 2006 году, российскими исследователями было показано, что сульбутиамин может быть эффективен в составе ком- 
плексной терапии у пациентов с синдромом хронической тазовой боли (СХТБ) [72].

\section{Терапевтические мишени сульбутиамина в наркологической практике}

Дефицит витамина $\mathrm{B}_{1}$ особенно актуален при алкогольной зависимости (АЗ). Он может приводить к выраженному неврологическому дефициту, инвалидизации и смертности [73]. Именно дефицит этого витамина лежит в основе патогенеза развития энцефалопатии Вернике, частого и опасного осложнения А3 [74].

Несмотря на то, что прицельных исследований по применению именно сульбутиамина (а не тиамина) при АЗ пока нет, это может рассматриваться как перспективное направление исследований, в связи со схожестью строения тиамина и сульбутиамина и со способностью сульбутиамина быстро метаболизироваться в клетках в тиамин, а также его хорошим проникновением через ГЭБ и внутрь клеток [74].

Показано, что сульбутиамин эффективен в устранении астенических и депрессивных симптомов в постабстинентном периоде и в периоде становления и поддержания ремиссии при различных формах химических зависимостей у подростков, по сравнению с контрольной группой подростков, получавшей плацебо. Было отмечено также, что в некоторых случаях для достижения стойкого положительного эффекта у этой категории пациентов необходима длительная (более 1 месяца) терапия сульбутиамином [15].

\section{Терапевтические мишени сульбутиамина при иных нозологиях Эректильная дисфункция}

Согласно одному из исследований, сульбутиамин может быть эффективным препаратом при лечении психогенной эректильной дисфункции (ЭД). В этом исследовании 20 пациентов с психогенной ЭД получали сульбутиамин в дозе 400 мг/сут (200 мг 2 раза в сутки) на протяжении 30 дней. После лечения эректильная функция улучшилась у 16 из 20 пациентов [75].

\section{Послеоперационный парез кишечника}

Сульбутиамин и другие липофильные соединения тиамина обладают способностью устранять или уменьшать послеоперационный парез кишечника. Возможно, это связано с усилением под их влиянием холинергической нейропередачи [10]. 


\section{Недержание мочи, нейрогенная дисфункция мочевого пузыря}

Сульбутиамин и другие липофильные производные тиамина способны уменьшать проблемы с недержанием мочи и нейрогенной дисфункцией мочевого пузыря (НДМП). Вероятно, это связано с модулированием ими холинергической и/или адренергической нейропередачи $[8,9]$.

\section{Сердечная недостаточность,}

\section{гипотонические состояния, аритмии}

Сульбутиамин и другие липофильные производные тиамина способны улучшать сократимость миокарда не только при хронической сердечной недостаточности $(\mathrm{XCH})$, связанной с бери-бери, но и при ХСН другого генеза, улучшают способность больных с гипотензией поддерживать нормальное артериальное давление. При проведении общей анестезии галотаном и другими подобными анестетиками сульбутиамин или фурсультиамин улучшают сократимость миокарда, снижают вероятность развития аритмий, уменьшают патологическую гиперчувствительность миокарда к адреналину, уменьшают гипотензию [7].

\section{Спортивная медицина}

Сульбутиамин, благодаря его энергизирующим, активирующим, умеренным стимулирующим и антиоксидантным свойствам, способности уменьшать мышечную утомляемость и повышать выносливость, используется в спортивной медицине в качестве допинга в соревновательном и восстановительном периодах. Так, в частности, из 16000 проб мочи спортсменов, проанализированных в российской антидопинговой лаборатории в 2009 году, 100 проб содержали сульбутиамин, причём это были пробы, взятые именно в соревновательный период [76].

\section{Заключение}

Как показывает проведённый нами обзор литературы, сульбутиамин может являться эффективным и безопасным средством коррекции астенических нарушений самого разного генеза, включая постинфекционные, посттравматические, постабстинентные и другие астенические состояния.

Кроме того, сульбутиамин может оказывать положительное влияние на когнитивное функционирование пациентов с БА, сосудистыми деменциями, другими психическими расстройствами (униполярные депрессии, БАР, шизофрения и РШС, различные ТР). Он также может способствовать уменьшению выраженности симптоматики при СДВГ и при РАС. 
По некоторым данным, сульбутиамин может сам обладать умеренной антидепрессивной и анксиолитической активностью. Поэтому он может применяться в составе комплексной терапии депрессивных расстройств, различных ТР.

Сульбутиамин метаболизируется в организме в тиамин. Поэтому его применение может быть уместным во всех тех случаях, когда уместно применение тиамина, например при АЗ и её последствиях (алкогольная энцефалопатия, алкогольная полинейропатия и др.), при диабетической ретинопатии и полинейропатии, при РПП, сопровождающихся дефицитом тиамина и др.

Благодаря своему влиянию на холинергические и другие системы организма, сульбутиамин также обладает рядом интересных соматотропных свойств, таких, как способность уменьшать послеоперационный парез кишечника, симптомы недержания мочи при НДМП, способность улучшать сократимость миокарда и уменьшать наклонность к гипотензии. Это позволяет применять его и в лечении соответствующих соматических патологий.

\section{Список литературы}

1. Inouye K., Katsura E. "Etiology and pathology of beriberi." In: Shimazono N, Katsura E, editors. Beriberi and Thiamine Igaku Shoin Ltd, 1965, pp. 1-28.

2. Lonsdale D. Thiamine tetrahydrofurfuryl disulfide: a little known therapeutic agent. Med Sci Monit, 2004, vol. 9, no. 10, pp. RA199-203.

3. Matsukawa T., Yurugi S., Matsuoka T. Products of the reaction between thiamine and ingredients of the plants of Allium genus: detection of allithiamine and its homologs. Science, 1953, vol. 3064, no.118, pp. 325-327. doi: 10.1126/ science.118.3064.325.

4. Lilly V.G., Barnett H.L., Anderson B.G. The effects of allithiamine on some thiamine-requiring organisms. Science, 1953, vol. 3071, no. 118, pp. 548-549. doi: 10.1126/science.118.3071.548.

5. Asahi Y. Polarographic determination of ascorbic acid, riboflavin, pteroylglutamic acid, 2-methyl-1,4-naphthohydroquinone diacetate, thiamine, niacinamide and thiamine propyl disulfide in multivitamin preparations. J Vitaminol (Kyoto), 1958, vol. 2, no. 4, pp. 118-125. doi: 10.5925/jnsv1954.4.118.

6. Lonsdale D. A review of the biochemistry, metabolism and clinical benefits of thiamin(e) and its derivatives. Evid Based Complement Alternat Med, 2006, vol. 1, no. 3, pp. 49-59. doi: 10.1093/ecam/nek009

7. Murakami S., Arakawa T., Nakagawa M. Therapeutic effect of O-butyryl-thiamine disulfide (BuTDS) on cardiac function under general anesthesia - with 
reference to improvement of ECG findings. Nihon Geka Hokan, 1966, vol. 5, no. 35 , pp. 879-904.

8. Tanaka H., Mizoguchi M., Fujimoto Y., Ishibe T. Clinical use of BuTDS in urological field. Hinyokika Kiyo, 1966, vol. 8, no. 12, pp. 811-822.

9. Gotoh K., Shinoda T., Kimura Y., Isogai K., Nishi M. Clinical experience with BuTDS in urological field. Hinyokika Kiyo, 1966, vol. 7, no. 12, pp. 709-712.

10. Tsuchida M., Kimura Y. Effects of BuTDS on postoperative intestinal paralysis. Hinyokika Kiyo, 1966, vol. 8, no. 12, pp. 808-810.

11. Fujihira E., Tarumoto Y., Ajioka M., Mori T., Nakazawa M. Analgesic effect of o-isobutyryl-thiamine disulfide on experimentally induced pain. Yakugaku Zasshi, 1973, vol. 3, no. 93, pp. 388-391.

12. Balestreri R., Bertolini S., Barban G. Effect of bis-(isobutyryloxy-2-ethyl)-1N-(amino-4-methyl-2-pyrimidyl-5) methyl formamido-2-propene-1-yl disulfide (Sulbutiamin) in neurasthenic and neuroastheniform syndromes. Arch Maragliano Patol Clin, 1979, no. 35, pp. 19-34.

13. Морозов П.В. Новое в лечении астении //Психиатрия и психофармакотерапия. 2005. № 3. С. 154-159.

14. Bettendorff L., Weekers L., Wins P., Schoffeniels E. Injection of sulbutiamine induces an increase in thiamine triphosphate in rat tissues. Biochem Pharmacol, 1990, vol. 11. no. 40, pp. 2557-2560. doi: 10.1016/0006-2952(90)90099-7

15. Гусев С.И., Трифонов О.И., Снигирева Г.Я. Применение энериона для лечения астенических состояния в период длительных ремиссий опийной наркомании у осужденных подростков //Вопросы наркологии. 2005. № 6. C. 21-28.

16. Bettendorff $\mathrm{L}$. The compartmentation of phosphorylated thiamine derivatives in cultured neuroblastoma cells. Biochim Biophys Acta, 1994, vol. 1, no. 1222, pp. 7-14. doi: 10.1016/0167-4889(94)90019-1

17. Volvert M.L., Seyen S., Piette M., Evrard B., Gangolf M., Plumier J.C., Bettendorff L. Benfotiamine, a synthetic S-acyl thiamine derivative, has different mechanisms of action and a different pharmacological profile than lipid-soluble thiamine disulfide derivatives. BMC Pharmacol, 2008, no. 8, pp. 10. doi: 10.1186/1471-2210-8-10

18. Новикова Л.Я. Астения - проблема современности //Уральский медицинский журнал. 2004. № 1. С. 22-26.

19. Micheau J., Durkin T.P., Destrade C., Rolland Y., Jaffard R. Chronic administration of sulbutiamine improves long term memory formation in mice: possible cholinergic mediation. Pharmacol Biochem Behav, 1985, vol. 2, no. 23, pp.195198. doi: 10.1016/0091-3057(85)90555-6 
20. Parada-Turska J., Turski W.A. Excitatory amino acid antagonists and memory: effect of drugs acting at N-methyl-D-aspartate receptors in learning and memory tasks. Neuropharmacology, 1990, vol. 12, no. 29, pp. 1111-1116. doi: 10.1016/0028-3908(90)90034-o

21. Staubli U., Rogers G., Lynch G. Facilitation of glutamate receptors enhances memory. Proc Natl Acad Sci USA, 1994, vol. 2, no. 91, pp. 777-781. doi: 10.1073/pnas.91.2.777

22. Puma C., Baudoin C., Bizot J.C. Effects of intraseptal infusions of N-methyl-D-aspartate receptor ligands on memory in an object recognition task in rats. Neurosci Lett, 1998, vol. 2, no. 244, pp. 97-100. doi: 10.1016/s03043940(98)00137-2

23. Pussinen R., Sirviö J. Effects of D-cycloserine, a positive modulator of N-methyl-D-aspartate receptors, and ST 587, a putative alpha-1 adrenergic agonist, individually and in combination, on the non-delayed and delayed foraging behaviour of rats assessed in the radial arm maze. J Psychopharmacol, 1999, vol. 2, no. 13, pp. 171-179. doi: 10.1177/026988119901300210

24. Levin E.D., Bettegowda C., Weaver T., Christopher N.C. Nicotine-dizocilpine interactions and working and reference memory performance of rats in the radial arm maze. Pharmacol Biochem Behav, 1998, vol. 3, no. 61, pp. 335-340. doi: 10.1016/s0091-3057(98)00109-9

25. Floresco S.B., Phillips A.G. Delay-dependent modulation of memory retrieval by infusion of a dopamine D1 agonist into the rat medial prefrontal cortex. Behav Neurosci, 2001, vol. 4, no. 115, pp. 934-939.

26. Bettendorff L., Hennuy B., De Clerck A., Wins P. Chloride permeability of rat brain membrane vesicles correlates with thiamine triphosphate content. Brain Res, 1994, vol. 1, no. 652, pp. 1571-60. doi: 10.1016/0006-8993(94)90331-x

27. Majid A.S., Yin Z.Q., Ji D. Sulphur antioxidants inhibit oxidative stress induced retinal ganglion cell death by scavenging reactive oxygen species but influence nuclear factor (erythroid-derived 2)-like 2 signalling pathway differently. Biol Pharm Bull, 2013, vol. 7, no. 36, pp. 1095-1110. doi: 10.1248/bpb.b13-00023

28. Kwag J., Majid A.S., Kang K.D. Evidence for neuroprotective effect of sulbutiamine against oxygen-glucose deprivation in rat hippocampal CA1 pyramidal neurons. Biol Pharm Bull, 2011, vol. 11, no. 34, pp. 1759-1764. doi: 10.1248/ bpb.34.1759

29. Kang K.D., Majid A.S., Kim K.A., Kang K., Ahn H.R., Nho C.W., Junge S.H. Sulbutiamine counteracts trophic factor deprivation induced apoptotic cell death in transformed retinal ganglion cells. Neurochem Res, 2010, vol. 11, no. 35, pp. 1828-1839. doi: 10.1007/s11064-010-0249-5 
30. Stahl S.M. Stahl's Essential Psychopharmacology: Neuroscientific Basis and Practical Applications. 4th Ed. Cambridge University Press, 2013. ISBN 9781107686465

31. Balzamo E., Vuillon-Cacciuttolo G. Facilitation of a state of wakefulness by semi-chronic treatment with sulbutiamin (Arcalion) in Macaca mulatta. Rev Electroencephalogr Neurophysiol Clin, 1982, vol. 4, no. 12, pp. 373-378. doi: 10.1016/s0370-4475(82)80029-4

32. Pan X., Gong N., Zhao J., Yu Z., Gu F., Chen J., Sun X., Zhao L., Yu M., Xu $Z$. Powerful beneficial effects of benfotiamine on cognitive impairment and beta-amyloid deposition in amyloid precursor protein/presenilin-1 transgenic mice. Brain, 2010, vol. 5, no. 133, pp. 1342-1351. doi: 10.1093/brain/awq069

33. Yang J., Li J.F., Zhao L. The Relationship Between GSK-3 and Mental Disorders. Sheng Li Ke Xue Jin Zhan, 2015, vol. 4, no. 46, pp. 250-254.

34. Alda M. Lithium in the treatment of bipolar disorder: pharmacology and pharmacogenetics. Mol Psychiatry, 2015, vol. 6, no. 20, pp. 661-670. doi: 10.1038/mp.2015.4

35. Kao C.Y., Hsu Y.C., Liu J.W., Lee D.C., Chung Y.F., Chiu I.M. The mood stabilizer valproate activates human FGF1 gene promoter through inhibiting HDAC and GSK-3 activities. J Neurochem, 2013, vol. 1, no. 126, pp. 4-18. doi: $10.1111 /$ jnc. 12292

36. Sümegi A. Quetiapine in bipolar disorders. Neuropsychopharmacol Hung, 2008, vol. 5, no. 10, pp. 281-291.

37. Aubry J.M., Schwald M., Ballmann E., Karege F. Early effects of mood stabilizers on the Akt/GSK-3beta signaling pathway and on cell survival and proliferation. Psychopharmacology (Berl), 2009, vol. 3. no. 205, pp. 419-429. doi: 10.1007/s00213-009-1551-2

38. Beaulieu J.M., Gainetdinov R.R., Caron M.G. Akt/GSK3 signaling in the action of psychotropic drugs. Annu Rev Pharmacol Toxicol, 2009, no. 49, pp. 327-347. doi: 10.1146/annurev.pharmtox.011008.145634

39. Douzenis A., Michopoulos I., Lykouras L. Sulbutiamine, an 'innocent' over the counter drug, interferes with therapeutic outcome of bipolar disorder. World J Biol Psychiatry, 2006, vol. 3, no. 7, pp. 183-185. doi: 10.1080/15622970500492616.

40. Lôo H., Poirier M.F., Ollat H., Elatki S. Effects of sulbutiamine (Arcalion 200) on psycho-behavioral inhibition in major depressive episodes. Encephale, 2000, vol. 2, no. 26, pp. 70-75.

41. McCormick L.M., Buchanan J.R., Onwuameze O.E., Pierson R.K., Paradiso S. Beyond alcoholism: Wernicke-Korsakoff syndrome in patients with psychiatric disorders. Cogn Behav Neurol, 2011, vol. 4, no. 24, pp. 209-216. doi: 10.1097/ WNN.0b013e31823f90c4 
42. Bizot J.C., Herpin A., Pothion S., Pirot S., Trovero F., Ollat H. Chronic treatment with sulbutiamine improves memory in an object recognition task and reduces some amnesic effects of dizocilpine in a spatial delayed-non-match-to-sample task. Prog Neuropsychopharmacol Biol Psychiatry, 2005, vol. 29, no. 6, pp. 928-935. doi: 10.1016/j.pnpbp.2005.04.035

43. Harrison R.A., Vu T., Hunter A.J. Wernicke's encephalopathy in a patient with schizophrenia. J Gen Intern Med, 2006, vol. 12. no. 21, pp. 8-11. doi: 10.1111/j.1525-1497.2006.00600.x

44. Sacks W., Esser A.H., Feitel B., Abbott K. Acetazolamide and thiamine: an ancillary therapy for chronic mental illness. Psychiatry Res, 1989, vol. 3, no. 28, pp. 279-288. doi: 10.1016/0165-1781(89)90208-4

45. Obrenovich M.E., Shamberger R.J., Lonsdale D. Altered heavy metals and transketolase found in autistic spectrum disorder. Biol Trace Elem Res, 2011, vol. 1-3, no. 144, pp. 475-486. doi: 10.1007/s12011-011-9146-2

46. Lonsdale D., Shamberger R.J., Obrenovich M.E. Dysautonomia in autism spectrum disorder: case reports of a family with review of the literature. Autism Res Treat, 2011, no 2011, pp. 129795. doi: 10.1155/2011/129795

47. Watanabe S., Yamakura S., Hirano K., Okumura Y., Aiba H. Case of infantile autism with pediatric Wernicke's encephalopathy due to severe eating disorder. No To Hattatsu, 2009, vol. 1, no. 41, pp. 43-46.

48. Lonsdale D., Shamberger R.J., Audhya T. Treatment of autism spectrum children with thiamine tetrahydrofurfuryl disulfide: a pilot study. Neuro Endocrinol Lett, 2002, vol. 4, no. 23, pp. 303-308.

49. Simon N. Infantile autism and Wernicke's encephalopathy. Med Hypotheses, 1990, vol. 3, no. 32, pp. 169-172. doi: 10.1016/0306-9877(90)90119-y

50. Hills J.I., Golub M.S., Bettendorff L., Keen C.L. The effect of thiamin tetrahydrofurfuryl disulfide on behavior of juvenile DBA/2J mice. Neurotoxicol Teratol, 2012, vol. 2, no. 34, pp. 242-252. doi: 10.1016/j.ntt.2011.07.006.

51. Brenner A. The effects of megadoses of selected B complex vitamins on children with hyperkinesis: controlled studies with long-term follow-up. J Learn Disabil, 1982, vol. 5, no. 15, pp. 258-264. doi: 10.1177/002221948201500501

52. Vichnar M. Experience with the administration of group B vitamins in children with the hyperkinetic syndrome. Cesk Psychiatr, 1988, vol. 4, no. 84, pp. 237-244.

53. Tikal K. Discussion of the article by M. Vichnar: Experience with the administration of group B vitamins to children with hyperkinetic syndrome. Cesk Psychiatr, 1989, vol. 3, no. 85, pp. 204-206.

54. Ollat H., Laurent B., Bakchine S., Michel B.F., Touchon J., Dubois B. Effects of the association of sulbutiamine with an acetylcholinesterase inhibitor in ear- 
ly stage and moderate Alzheimer disease. Encephale, 2007, vol. 2, no. 33, pp. 211-215. doi: 10.1016/s0013-7006(07)91552-3

55. Mimori Y., Katsuoka H., Nakamura S. Thiamine therapy in Alzheimer's disease. Metab Brain Dis, 1996, vol. 11, no. 1, pp. 89-94. doi: 10.1007/BF02080934

56. Погосова Г.В. Психоэмоциональные расстройства у больных сердечно-сосудистыми заболеваниями: вопросы лечения //Кардиоваскулярная терапия и профилактика. 2006. Т. 5. № 2. С. 94-99.

57. Лебедев М.А., Палатов С.Ю., Ковров Г.В. Усталость и ее проявления //Русский медицинский журнал. 2014. Т. 22. №4. С. 282-286.

58. Хасанова Д., Мухутдинова Э., Житкова Ю. Энерион (сульбутиамин) в лечении постинсультного астенического синдрома //Врач. 2008. № 7. С. 66-69.

59. Головина А.Г. Энерион в терапии астенических расстройств у подростков в амбулаторной психиатрической практике //Психиатрия. 2004. Т. 9. № 3. С. 43-49.

60. Михайлова Н.М. Применение энериона для лечения астенических расстройств в психогериатрической практике //Психиатрия. 2004. Т. 10. № 4. C. $65-75$.

61. Гурак С.В., Парфенов В.А. Астения после инсульта и инфаркта миокарда и ее лечении энерионом //Клиническая геронтология. 2005. Т. 11. № 8. С. 9-12.

62. Левин О.С., Слизкова Ю.Б. Применение энериона при лечении астенических расстройств у больных, перенесших легкую черепно-мозговую травму // Журнал неврологии и психиатрии им. С.С. Корсакова. 2007. №5. С. 44-48.

63. Вейн А.М., Федотова А.В., Гордеев С.А. Энерион - эффективное и безопасное средство для лечения астении у больных с психовегетативным синдромом //Русский медицинский журнал. 2004. Т. 12. № 10. С. 631-634.

64. Бутрина Л.В. Оптимизация фармакотерапии астенического синдрома у больных с соматической патологией. Автореф. дис. ... канд. мед. наук. Волгоград, 2004.

65. Божкова Е.Д. Динамика нервно-психических расстройств в процессе реабилитации пациентов в раннем восстановительном периоде инсульта. Автореф. дис. ... канд. мед. наук. Нижний Новгород, 2006.

66. Сафронова Н.С., Найдич С.И., Полевик И.В. Влияние физических нагрузок и приема энериона на формирование неспецифических адаптационных реакций организма футболистов //Ученые записки Таврического национального университета им. В.И. Вернадского Серия «Биология, химия». 2009. T. 22. № 4. C. 152-157.

67. Смирнов А.А. Клинико-экспериментальное обоснование оптимизации восстановительной терапии больных дисциркуляторной энцефалопатией. Автореф. дис. ... канд. мед. наук. Иваново, 2006. 
68. Бухановский А.О., Галкин К.Ю., Мирзаева Л.М., Бухановская О.А. Энерион (сульбутиамин) в лечении функциональной астении. Южно-российский медицинский журнал. 2002. № 5. С. 26-29.

69. Бондарчук Е.Ю. Клинико-иммунологические и терапевтические аспекты неврастении в зрелом возрасте. Автореф. дис. ... канд. мед. наук. Челябинск, 2004.

70. Литвинович Е.Ф., Лангеман Т.И., Литвинович С.Ф. Применение сульбутиамина (энериона) в комбинированном лечении больных симптоматической фокальной эпилепсией //Журнал неврологии и психиатрии им. С.С. Корсакова 2006. № 2. С. 68-70.

71. Kiew K.K., Wan Mohamad W.B., Ridzuan A., Mafauzy M. Effects of sulbutiamine on diabetic polyneuropathy: an open randomised controlled study in type 2 diabetics. Malays J Med Sci, 2002, vol. 1, no. 19, pp. 21-27.

72. Линева О.И. Энерион в комплексной терапии больных с синдромом хронической тазовой боли //Российский вестник акушера-гинеколога. 2006. №2. C. 41-43.

73. Manzardo A.M., He J., Poje A., Penick E.C., Campbell J., Butler M.G. Double-blind, randomized placebo-controlled clinical trial of benfotiamine for severe alcohol dependence. Drug Alcohol Depend, 2013, vol. 2. no. 133, pp. 562-570. doi: 10.1016/j.drugalcdep.2013.07.035

74. Donovan A., Perelman M. BNF recommendations for the treatment of Wernicke's encephalopathy: lost in translation? Alcohol Alcohol, 2013, vol. 6, no. 48, pp. 743. doi: 10.1093/alcalc/agt145

75. Dmitriev D.G., Gamidov S.I., Permiakova O.V. Clinical efficacy of the drug enerion in the treatment of patients with psychogenic (functional) erectile dysfunction. Urologiia, 2005, vol. 1, pp. 32-35.

76. Sobolevsky T., Rodchenkov G. Sulbutiamine in sports. Drug Test Anal, 2010, vol. 11-12, no. 2, pp. 643-646. doi: 10.1002/dta.183

\section{References}

1. Inouye K., Katsura E. "Etiology and pathology of beriberi.” In: Shimazono N, Katsura E, editors. Beriberi and Thiamine Igaku Shoin Ltd, 1965, pp. 1-28.

2. Lonsdale D. Thiamine tetrahydrofurfuryl disulfide: a little known therapeutic agent. Med Sci Monit, 2004, vol. 9, no. 10, pp. RA199-203.

3. Matsukawa T., Yurugi S., Matsuoka T. Products of the reaction between thiamine and ingredients of the plants of Allium genus: detection of allithiamine and its homologs. Science, 1953, vol. 3064, no.118, pp. 325-327. doi: 10.1126/ science.118.3064.325 
4. Lilly V.G., Barnett H.L., Anderson B.G. The effects of allithiamine on some thiamine-requiring organisms. Science, 1953, vol. 3071, no. 118, pp. 548-549. doi: 10.1126/science.118.3071.548

5. Asahi Y. Polarographic determination of ascorbic acid, riboflavin, pteroylglutamic acid, 2-methyl-1,4-naphthohydroquinone diacetate, thiamine, niacinamide and thiamine propyl disulfide in multivitamin preparations. J Vitaminol (Kyoto), 1958, vol. 2, no. 4, pp. 118-125. doi: 10.5925/jnsv1954.4.118

6. Lonsdale D. A review of the biochemistry, metabolism and clinical benefits of thiamin(e) and its derivatives. Evid Based Complement Alternat Med, 2006, vol. 1, no. 3, pp. 49-59. doi: 10.1093/ecam/nek009

7. Murakami S., Arakawa T., Nakagawa M. Therapeutic effect of O-butyryl-thiamine disulfide (BuTDS) on cardiac function under general anesthesia - with reference to improvement of ECG findings. Nihon Geka Hokan, 1966, vol. 5, no. 35 , pp. 879-904.

8. Tanaka H., Mizoguchi M., Fujimoto Y., Ishibe T. Clinical use of BuTDS in urological field. Hinyokika Kiyo, 1966, vol. 8, no. 12, pp. 811-822.

9. Gotoh K., Shinoda T., Kimura Y., Isogai K., Nishi M. Clinical experience with BuTDS in urological field. Hinyokika Kiyo, 1966, vol. 7, no. 12, pp. 709-712.

10. Tsuchida M., Kimura Y. Effects of BuTDS on postoperative intestinal paralysis. Hinyokika Kiyo, 1966, vol. 8, no. 12, pp. 808-810.

11. Fujihira E., Tarumoto Y., Ajioka M., Mori T., Nakazawa M. Analgesic effect of o-isobutyryl-thiamine disulfide on experimentally induced pain. Yakugaku Zasshi, 1973, vol. 3, no. 93, pp. 388-391.

12. Balestreri R., Bertolini S., Barban G. Effect of bis-(isobutyryloxy-2-ethyl)-1N-(amino-4-methyl-2-pyrimidyl-5) methyl formamido-2-propene-1-yl disulfide (Sulbutiamin) in neurasthenic and neuroastheniform syndromes. Arch Maragliano Patol Clin, 1979, no. 35, pp. 19-34.

13. Morozov P.V. Novoe v lechenii astenii [News in therapy of asthenia]. Psychiatry and psychopharmacotherapy, 2005, no. 3, pp. 154-159.

14. Bettendorff L., Weekers L., Wins P., Schoffeniels E. Injection of sulbutiamine induces an increase in thiamine triphosphate in rat tissues. Biochem Pharmacol, 1990, vol. 11. no. 40, pp. 2557-2560. doi: 10.1016/0006-2952(90)90099-7

15. Gusev S.I., Trifonov O.I., Snigireva G.Y. Primenenie eneriona dlya lecheniya astenicheskih sostoyanij v period dlitel'nyh remissij opijnoj narkomanii u osuzhdennyh podrostkov [The use of enerion fot the therapy of asthenic states in opioid use disorder in remission in criminal adolescents]. Voprosy narkologii, 2005, no. 6, pp. 21-28. 
16. Bettendorff $\mathrm{L}$. The compartmentation of phosphorylated thiamine derivatives in cultured neuroblastoma cells. Biochim Biophys Acta, 1994, vol. 1, no. 1222, pp. 7-14. doi: 10.1016/0167-4889(94)90019-1

17. Volvert M.L., Seyen S., Piette M., Evrard B., Gangolf M., Plumier J.C., Bettendorff L. Benfotiamine, a synthetic S-acyl thiamine derivative, has different mechanisms of action and a different pharmacological profile than lipid-soluble thiamine disulfide derivatives. BMC Pharmacol, 2008, no. 8, pp. 10. doi: 10.1186/1471-2210-8-10

18. Novikova L.Y. Astenija - problema sovremennosti [Asthenia - a modern problem]. Ural'skij meditsinskij zhurnal, 2004, no. 1, pp. 22-26.

19. Micheau J., Durkin T.P., Destrade C., Rolland Y., Jaffard R. Chronic administration of sulbutiamine improves long term memory formation in mice: possible cholinergic mediation. Pharmacol Biochem Behav, 1985, vol. 2, no. 23, pp. 195-198. doi: 10.1016/0091-3057(85)90555-6

20. Parada-Turska J., Turski W.A. Excitatory amino acid antagonists and memory: effect of drugs acting at N-methyl-D-aspartate receptors in learning and memory tasks. Neuropharmacology, 1990, vol. 12, no. 29, pp. 1111-1116. doi: 10.1016/0028-3908(90)90034-o

21. Staubli U., Rogers G., Lynch G. Facilitation of glutamate receptors enhances memory. Proc Natl Acad Sci USA, 1994, vol. 2, no. 91, pp. 777-781. doi: 10.1073/pnas.91.2.777

22. Puma C., Baudoin C., Bizot J.C. Effects of intraseptal infusions of N-methyl-D-aspartate receptor ligands on memory in an object recognition task in rats. Neurosci Lett, 1998, vol. 2, no. 244, pp. 97-100. doi: 10.1016/s0304-3940(98)00137-2

23. Pussinen R., Sirviö J. Effects of D-cycloserine, a positive modulator of N-methyl-D-aspartate receptors, and ST 587, a putative alpha-1 adrenergic agonist, individually and in combination, on the non-delayed and delayed foraging behaviour of rats assessed in the radial arm maze. J Psychopharmacol, 1999, vol. 2, no. 13, pp. 171-179. doi: 10.1177/026988119901300210

24. Levin E.D., Bettegowda C., Weaver T., Christopher N.C. Nicotine-dizocilpine interactions and working and reference memory performance of rats in the radial arm maze. Pharmacol Biochem Behav, 1998, vol. 3, no. 61, pp. 335-340. doi: 10.1016/s0091-3057(98)00109-9

25. Floresco S.B., Phillips A.G. Delay-dependent modulation of memory retrieval by infusion of a dopamine D1 agonist into the rat medial prefrontal cortex. Behav Neurosci, 2001, vol. 4, no. 115, pp. 934-939.

26. Bettendorff L., Hennuy B., De Clerck A., Wins P. Chloride permeability of rat brain membrane vesicles correlates with thiamine triphosphate content. Brain Res, 1994, vol. 1, no. 652, pp. 1571-60. doi: 10.1016/0006-8993(94)90331-x 
27. Majid A.S., Yin Z.Q., Ji D. Sulphur antioxidants inhibit oxidative stress induced retinal ganglion cell death by scavenging reactive oxygen species but influence nuclear factor (erythroid-derived 2)-like 2 signalling pathway differently. Biol Pharm Bull, 2013, vol. 7, no. 36, pp. 1095-1110. doi: 10.1248/bpb.b13-00023

28. Kwag J., Majid A.S., Kang K.D. Evidence for neuroprotective effect of sulbutiamine against oxygen-glucose deprivation in rat hippocampal CA1 pyramidal neurons. Biol Pharm Bull, 2011, vol. 11, no. 34, pp. 1759-1764. doi: 10.1248/ bpb.34.1759

29. Kang K.D., Majid A.S., Kim K.A., Kang K., Ahn H.R., Nho C.W., Junge S.H. Sulbutiamine counteracts trophic factor deprivation induced apoptotic cell death in transformed retinal ganglion cells. Neurochem Res, 2010, vol. 11, no. 35, pp. 1828-1839. doi: 10.1007/s11064-010-0249-5

30. Stahl S.M. Stahl's Essential Psychopharmacology: Neuroscientific Basis and Practical Applications. 4th Ed. Cambridge University Press, 2013. ISBN 9781107686465

31. Balzamo E., Vuillon-Cacciuttolo G. Facilitation of a state of wakefulness by semi-chronic treatment with sulbutiamin (Arcalion) in Macaca mulatta. Rev Electroencephalogr Neurophysiol Clin, 1982, vol. 4, no. 12, pp. 373-378. doi: 10.1016/s0370-4475(82)80029-4

32. Pan X., Gong N., Zhao J., Yu Z., Gu F., Chen J., Sun X., Zhao L., Yu M., Xu $Z$. Powerful beneficial effects of benfotiamine on cognitive impairment and beta-amyloid deposition in amyloid precursor protein/presenilin-1 transgenic mice. Brain, 2010, vol. 5, no. 133, pp. 1342-1351. doi: 10.1093/brain/awq069

33. Yang J., Li J.F., Zhao L. The Relationship Between GSK-3 and Mental Disorders. Sheng Li Ke Xue Jin Zhan, 2015, vol. 4, no. 46, pp. 250-254.

34. Alda M. Lithium in the treatment of bipolar disorder: pharmacology and pharmacogenetics. Mol Psychiatry, 2015, vol. 6, no. 20, pp. 661-670. doi: 10.1038/ mp. 2015.4

35. Kao C.Y., Hsu Y.C., Liu J.W., Lee D.C., Chung Y.F., Chiu I.M. The mood stabilizer valproate activates human FGF1 gene promoter through inhibiting HDAC and GSK-3 activities. J Neurochem, 2013, vol. 1, no. 126, pp. 4-18. doi: $10.1111 /$ jnc. 12292

36. Sümegi A. Quetiapine in bipolar disorders. Neuropsychopharmacol Hung, 2008, vol. 5, no. 10, pp. 281-291.

37. Aubry J.M., Schwald M., Ballmann E., Karege F. Early effects of mood stabilizers on the Akt/GSK-3beta signaling pathway and on cell survival and proliferation. Psychopharmacology (Berl), 2009, vol. 3. no. 205, pp. 419-429. doi: 10.1007/s00213-009-1551-2 
38. Beaulieu J.M., Gainetdinov R.R., Caron M.G. Akt/GSK3 signaling in the action of psychotropic drugs. Annu Rev Pharmacol Toxicol, 2009, no. 49, pp. 327-347. doi: 10.1146/annurev.pharmtox.011008.145634

39. Douzenis A., Michopoulos I., Lykouras L. Sulbutiamine, an 'innocent' over the counter drug, interferes with therapeutic outcome of bipolar disorder. World J Biol Psychiatry, 2006, vol. 3, no. 7, pp. 183-185. doi: 10.1080/15622970500492616.

40. Lôo H., Poirier M.F., Ollat H., Elatki S. Effects of sulbutiamine (Arcalion 200) on psycho-behavioral inhibition in major depressive episodes. Encephale, 2000, vol. 2, no. 26, pp. 70-75.

41. McCormick L.M., Buchanan J.R., Onwuameze O.E., Pierson R.K., Paradiso S. Beyond alcoholism: Wernicke-Korsakoff syndrome in patients with psychiatric disorders. Cogn Behav Neurol, 2011, vol. 4, no. 24, pp. 209-216. doi: 10.1097/ WNN.0b013e31823f90c4

42. Bizot J.C., Herpin A., Pothion S., Pirot S., Trovero F., Ollat H. Chronic treatment with sulbutiamine improves memory in an object recognition task and reduces some amnesic effects of dizocilpine in a spatial delayed-non-match-to-sample task. Prog Neuropsychopharmacol Biol Psychiatry, 2005, vol. 29, no. 6, pp. 928-935. doi: 10.1016/j.pnpbp.2005.04.035

43. Harrison R.A., Vu T., Hunter A.J. Wernicke's encephalopathy in a patient with schizophrenia. J Gen Intern Med, 2006, vol. 12. no. 21, pp. 8-11. doi: 10.1111/j.1525-1497.2006.00600.x

44. Sacks W., Esser A.H, Feitel B., Abbott K. Acetazolamide and thiamine: an ancillary therapy for chronic mental illness. Psychiatry Res, 1989, vol. 3, no. 28, pp. 279-288. doi: 10.1016/0165-1781(89)90208-4

45. Obrenovich M.E., Shamberger R.J., Lonsdale D. Altered heavy metals and transketolase found in autistic spectrum disorder. Biol Trace Elem Res, 2011, vol. 1-3, no. 144, pp. 475-486. doi: 10.1007/s12011-011-9146-2

46. Lonsdale D., Shamberger R.J., Obrenovich M.E. Dysautonomia in autism spectrum disorder: case reports of a family with review of the literature. Autism Res Treat, 2011, no 2011, pp. 129795. doi: 10.1155/2011/129795

47. Watanabe S., Yamakura S., Hirano K., Okumura Y., Aiba H. Case of infantile autism with pediatric Wernicke's encephalopathy due to severe eating disorder. No To Hattatsu, 2009, vol. 1, no. 41, pp. 43-46.

48. Lonsdale D., Shamberger R.J., Audhya T. Treatment of autism spectrum children with thiamine tetrahydrofurfuryl disulfide: a pilot study. Neuro Endocrinol Lett, 2002, vol. 4, no. 23, pp. 303-308.

49. Simon N. Infantile autism and Wernicke's encephalopathy. Med Hypotheses, 1990, vol. 3, no. 32, pp. 169-172. doi: 10.1016/0306-9877(90)90119-y 
50. Hills J.I., Golub M.S., Bettendorff L., Keen C.L. The effect of thiamin tetrahydrofurfuryl disulfide on behavior of juvenile DBA/2J mice. Neurotoxicol Teratol, 2012, vol. 2, no. 34, pp. 242-252. doi: 10.1016/j.ntt.2011.07.006.

51. Brenner A. The effects of megadoses of selected B complex vitamins on children with hyperkinesis: controlled studies with long-term follow-up. J Learn Disabil, 1982, vol. 5, no. 15, pp. 258-264. doi: 10.1177/002221948201500501

52. Vichnar M. Experience with the administration of group B vitamins in children with the hyperkinetic syndrome. Cesk Psychiatr, 1988, vol. 4, no. 84, pp. 237-244.

53. Tikal K. Discussion of the article by M. Vichnar: Experience with the administration of group B vitamins to children with hyperkinetic syndrome. Cesk Psychiatr, 1989, vol. 3, no. 85, pp. 204-206.

54. Ollat H., Laurent B., Bakchine S., Michel B.F., Touchon J., Dubois B. Effects of the association of sulbutiamine with an acetylcholinesterase inhibitor in early stage and moderate Alzheimer disease. Encephale, 2007, vol. 2, no. 33, pp. 211-215. doi: 10.1016/s0013-7006(07)91552-3

55. Mimori Y., Katsuoka H., Nakamura S. Thiamine therapy in Alzheimer's disease. Metab Brain Dis, 1996, vol. 11, no. 1, pp. 89-94. doi: 10.1007/BF02080934

56. Pogosova G.V. Psikhoemotsional'nye rasstrojstva u bol'nyh serdechno-sodudistymi zabolevanijami: voprosy lechenija [Psychoemotional disorders in patients with cardiovascular disorders: implications for therapy]. Kardiovaskuljarnaja terapija i profilaktika, 2006, vol. 5, no. 2, pp. 94-99.

57. Lebedev M.A., Palatov S.Yu., Kovrov G.V. Ustalost' i eje projavlenija [Tiredness and its manifestations]. Russkij medicinskij zhurnal, 2014, vol. 22, no. 4, pp. 282-286.

58. Khasanova D., Mukhutdinova E., Zhitkova Yu. Enerion (sulbutiamin) v lechenij postinsult'nogo astenicheskogo sindroma [Enerion (sulbuthiamine) in the treatment of poststroke asthenia]. Vrach, 2008, no. 7, pp. 66-69.

59. Golovina A.G. Enerion v terapii astenicheskih rasstroistv u podrostkov v ambulatornoj psikhiatricheskoj praktike [Enerion in the treatment of asthenic states in adolescents in ambulatory psychiatric practice]. Psikhiatrija, 2004, vol. 9, no. 3, pp. 43-49.

60. Mikhajlova N.M. Primenenie eneriona dlya lechenija astenicheskih rasstroistv v psikhogeriatricheskoj praktike [The use of enerion for the treatment of asthenic states in psycho-geriatric practice]. Psikhiatrija, 2004, vol. 9, no. 3, pp. 65-75.

61. Gurak S.V., Parfenov V.A. Astenija posle insul'ta i infarkta miokarda i ee lechenie enerionom [Post-stroke and post-infarction asthenia and its treatment with enerion]. Klinicheskaja gerontologija, 2005, vol. 11, no. 8, pp. 9-12.

62. Levin O.S., Slizkova Yu.B. Primenenie eneriona pri lechenii astenicheskih rasstroistv u bol'nyh, perenjosshih ljegkuju cherepno-mozgovuju travmu [The 
use of enerion in patients who have been suffered from mild brain trauma]. Zhurnal nevrologii i psikhiatrii im. S.S. Korsakova, 2007, no. 5, pp. 44-48.

63. Vein A.M., Fedotova A.V., Gordeev S.A. Enerion - effektivnoe i bezopasnoe sredstvo dlya lechenija astenii u bol'nyh s psikhovegetativnym sindromom [Enerion - an effective and safe drug for the treatment of asthenia in patients with a psycho-vegetative syndrome]. Russkij medicinskij zhurnal, 2004, vol. 12, no. 10, pp. 631-634.

64. Butrina L.V. Optimizatsija farmakoterapii astenicheskogo sindroma u bol'nyh s somaticheskoj patologiej [The problem of optimal pharmacotherapy of asthenic syndromes in patients with various medical disorders]. Candidate of medical sciences thesis, Volgograd, 2004.

65. Bozhkova E.D. Dinamika nervno-psikhicheskih rasstroistv v protcesse reabilitatsii patsientov $\mathrm{v}$ rannem vosstanovitel'nom periode insul'ta [The dynamics of mental and psychological disorders in patients in early rehabilitation phase after stroke]. Candidate of medical sciences thesis, Nizhny Novgorod, 2006.

66. Safronova N.S., Naidich S.I., Polevik I.V. Vlijanie fizicheskih nagruzok i priema eneriona na formirovanie nespetsificheskih adaptatsionnyh reaktsij organizma futbolistov [The effect of physical activity and the use of enerion on the non-specific adaptive reactions of football players]. Uchenye zapiski Tavricheskogo natsional'nogo universiteta imeni V.I. Vernadskogo. Serija "Biologija, khimija", 2009, vol. 22, no. 4, pp. 152-157.

67. Smirnov A.A. Kliniko-eksperimental'noe obosnovanie optimizatsii vosstanovitel'noj terapii bol'nyh distsirkuljatornoj entsefalopatiej [A clinical and experimental grounding for the optimization of rehabilitation therapy in patients with circulatory encephalopathy]. Candidate of medical sciences thesis, Ivanovo, 2006.

68. Bukhanovskij A.O., Galkin K.Yu., Mirzaeva L.M., Bukhanovskaja O.A. Enerion (sul'butiamin) v lechenii funktsional'noj astenii [Enerion (sulbuthiamine) in the treatment of functional asthenic states]. Juzhno-rossijskij meditsinskij zhurnal, 2002, no. 5, pp. 26-29.

69. Bondarchuk E.Yu. Kliniko-immunologicheskie i terapevticheskie aspekty nevrastenii $v$ zrelom vozraste [Clinical, immunological and therapeutic aspects of neurasthenia in adult life]. Candidate of medical sciences thesis, Chelyabinsk, 2004.

70. Litvinovich E.F., Langeman T.I., Litvinovich S.F. Primenenie sul'butiamina (eneriona) v kombinirovannom lechenii bol'nyh s simptomaticheskoj fokal'noj epilepsiej [The use of sulbuthiamine (enerion) in the combined treatment of patients with symptomatic focal epilepsy]. Zhurnal nevrologii i psikhiatrii im. S.S. Korsakova, 2006, no. 2, pp. 68-70.

71. Kiew K.K., Wan Mohamad W.B., Ridzuan A., Mafauzy M. Effects of sulbutiamine on diabetic polyneuropathy: an open randomised controlled study in type 2 diabetics. Malays J Med Sci, 2002, vol. 1, no. 19, pp. 21-27. 
72. Linjeva O.I. Enerion v kompleksnoj terapii bol'nyh s sindromom chronicheskoj tazovoj boli [Enerion in the combination therapy of patients with chronic pelvic pain syndrome]. Rossijskij vestnik akushera-ginekologa, 2006, no. 2, pp. 41-43.

73. Manzardo A.M., He J., Poje A., Penick E.C., Campbell J., Butler M.G. Double-blind, randomized placebo-controlled clinical trial of benfotiamine for severe alcohol dependence. Drug Alcohol Depend, 2013, vol. 2. no. 133, pp. 562-570. doi: 10.1016/j.drugalcdep.2013.07.035

74. Donovan A., Perelman M. BNF recommendations for the treatment of Wernicke's encephalopathy: lost in translation? Alcohol Alcohol, 2013, vol. 6, no. 48, pp. 743. doi: 10.1093/alcalc/agt145

75. Dmitriev D.G., Gamidov S.I., Permiakova O.V. Clinical efficacy of the drug enerion in the treatment of patients with psychogenic (functional) erectile dysfunction. Urologiia, 2005, vol. 1, pp. 32-35.

76. Sobolevsky T., Rodchenkov G. Sulbutiamine in sports. Drug Test Anal, 2010, vol. 11-12, no. 2, pp. 643-646. doi: 10.1002/dta.183

\section{ДАННЫЕ ОБ АВТОРАХ}

Беккер Роман Александрович, программист, инженер-математик, магистр в области компьютерных наук, исследователь лаборатории автономных роботов, факультет электроники и компьютерных наук Университет им. Давида Бен-Гуриона в Негеве б. Бен-Гурион, г. Беэр-Шева, 8410501, Израиль rbekker1@gmail.com

Быков Юрий Витальевич, врач анестезиолог-реаниматолог, врач психиатр-нарколог, кандидат медицинских наук, ассистент кафедры анестезиологии, реаниматологии и скорой медицинской помощи, педиатрический факультет

ФГБОУ ВО «Ставропольский государственный медицинский университет Минздрава России»

ул. Мира, 310, г. Ставрополь, 355017, Российская Федераџия yubykov@gmail.com

\section{DATA ABOUT THE AUTHORS}

Bekker Roman Alexandrovich, Programmer, Computer Engineer, Magister of Computer Science, Research Officer at the Laboratory of Autonomous Security Systems (Robotics), Faculty of Electrical and Computer Engineering 
Ben-Gurion University of the Negev

bulv. Ben-Gurion, Beer-Sheva, 8410501, Israel

rbekker1@gmail.com

ORCID: 0000-0002-0773-3405

Bykov Yuriy Vitalievich, anesthesiologist, psychiatrist, addiction medicine specialist, Candidate of Medical Sciences, Teaching Assistant at the Department of Anesthesiology, Reanimatology and Emergency Care, Department of Pediatrics Stavropol State Medical University 310, Mira Str., Stavropol, 355017, Russian Federation yubykov@gmail.com

ORCID: 0000-0003-4705-3823 